\title{
Characterization of Surface Structure and
}

\section{Oxidation/Reduction Behaviour of $\mathrm{Pd}-\mathrm{Pt} / \mathrm{Al}_{2} \mathrm{O}_{3}$ Model Catalysts}

Natalia M. Martin, ${ }^{* \dagger}$ Johan Nilsson, $^{\dagger}$ Magnus Skoglundh, ${ }^{\dagger}$ Emma C. Adams, ${ }^{\dagger}$ Xueting Wang, ${ }^{\dagger}$ Peter Velin, ${ }^{\dagger}$ Gudmund Smedler, ${ }^{\ddagger}$ Agnes Raj, ${ }^{\uparrow}$ David Thompsett, ${ }^{\llbracket}$ Hidde H. Brongersma, ${ }^{\S}$ Thomas Grehl, $\|$ Giovanni Agostini, ${ }^{\perp}$ Olivier Mathon, ${ }^{\perp}$ Stefan Carlson, \# Katarina Norén, \# Francisco J. Martinez-Casado,\# Zdenek Matej, \# Olivier Balmes, \# and Per-Anders Carlsson ${ }^{\dagger}$

Competence Centre for Catalysis, Chalmers University of Technology, Gothenburgh, 412 96, Sweden, Johnson Matthey AB, Västra Frölunda, 421 31, Sweden, Johnson Matthey Technology Centre, Blounts Court, Sonning Common, Reading, RG4 9NH, UK, Department of Applied Physics, Eindhoven University of Technology, Eindhoven, 5600, The Netherlands, ION-TOF GmbH, Münster, Germany, European Synchrotron Radiation Facility, Grenoble, 38043, France, and MAX-IV Laboratory, Lund University, Lund, 221 00, Sweden

E-mail: Natalia.Martin@chalmers.se

Phone: +46 (0)31-772 2904 . 


\begin{abstract}
Structural and morphological characterisation of bimetallic $\mathrm{Pd}-\mathrm{Pt} / \mathrm{Al}_{2} \mathrm{O}_{3}$ model catalysts are performed using X-ray diffraction, X-ray absorption spectroscopy, transmission electron microscopy and $\mathrm{CO}$ chemisorption. Further, the catalysts were studied under oxidising and reducing conditions using both X-ray absorption spectroscopy and low-energy ion scattering spectroscopy. For the as-prepared catalysts, the existence of alloyed bimetallic Pd-Pt particles and of (tetragonal) PdO were found for the samples calcined at $800{ }^{\circ} \mathrm{C} . \mathrm{PdO}$ is present in form of crystals at the surface of the Pd-Pt particles or as isolated PdO crystals on the support oxide. Bimetallic Pd-Pt nanoparticles were only formed on the Pd-Pt catalysts after calcination at $800{ }^{\circ} \mathrm{C}$. The results show that the Pd-Pt nanoparticles undergo reversible changes in surface structure composition and chemical state in response to oxidising or reducing conditions. Under oxidising conditions $\mathrm{Pd}$ segregates to the shell and oxidises forming $\mathrm{PdO}$, while under reducing conditions regions with metallic $\mathrm{Pd}$ and $\mathrm{Pd}-\mathrm{Pt}$ alloys were observed at the surface. No bimetallic Pd-Pt nanoparticles were observed for the sample initially calcined at $500{ }^{\circ} \mathrm{C}$, but instead isolated monometallic particles, where small Pt particles are easily oxidised under $\mathrm{O}_{2}$ treatment. In the monometallic catalysts, the $\mathrm{Pd}$ is found to be completely oxidised already after calcination and to consist of metallic $\mathrm{Pd}$ after reductive treatment.
\end{abstract}

${ }^{*}$ To whom correspondence should be addressed

${ }^{\dagger}$ Chalmers University

$\ddagger$ Johnson Matthey, Sweden

IJohnson Matthey, UK

${ }^{\S}$ Eindhoven University

IION-TOF

${ }^{\perp} \mathrm{ESRF}$

\# MAX IV Laboratory 


\section{Introduction}

Bimetallic catalysts are used in many chemical processes such as catalytic reforming, ${ }^{1-4}$ pollution control ${ }^{1}$ and energy conversion. ${ }^{5-7}$ Thanks to high catalytic activity and selectivity as well as durability that often is superior to the monometallic counterparts, bimetallic catalysts represents a particularly important type of catalysts. ${ }^{8-11}$ As for most catalysts, the surface structure and nanoscale composition of bimetallic catalysts may change considerably during the course of a reaction, which can have dramatic effects on the performance of the catalyst $^{1,12-14}$. Further, restructuring in response to different gas treatments paves the way for controlled engineering of catalysts with enhanced activity and selectivity. Still, however, deep understanding of restructuring phenomena of many bimetallic catalytic systems is lacking. For example, divergent restructuring behaviours have been reported for $\mathrm{Rh}-\mathrm{Pd}$ and Pd-Pt catalysts under the same reaction conditions. ${ }^{15}$

One system of particular interest for automotive pollution control is the bimetallic palladiumbased catalysts for oxidation of hydrocarbons and in particular methane $\left(\mathrm{CH}_{4}\right)$. Recent studies have shown that supported Pd-Pt catalysts exhibit a slight increase in $\mathrm{CH}_{4}$ oxidation activity with time on stream and higher long-term stability than supported Pd alone ${ }^{16-19}$ and even less sintering in oxidative environments compared to supported Pt only. ${ }^{20}$ As automotive catalysts frequently operate in dynamic environments, alternating between e.g. oxidising and reducing conditions, the surface composition and structure of the catalyst and thus the catalytic properties change correspondingly. The open literature contains contradictory reports on the restructuring behaviour of alloyed Pd-Pt nanoparticles. A few studies have reported a reduced surface segregation, ${ }^{21}$ while others have found alloy formation and segregation of $\mathrm{Pd}$ on the surface of bimetallic particles under both oxidative or reducing environments. ${ }^{22-26}$ Thus it is important to further clarify how such treatments change the catalyst morphology and understand how this in turn determines the catalytic properties.

The present study aims at investigating how the calcination conditions, and oxidative and reductive treatments influence the surface composition and alloy formation of alumina 
$\left(\mathrm{Al}_{2} \mathrm{O}_{3}\right)$ supported Pd-Pt model catalysts. The combination of transmission electron microscopy (TEM), X-ray diffraction (XRD), X-ray absorption spectroscopy (XAS) and lowenergy ion scattering spectroscopy (LEIS), provide evidence that calcination of as prepared catalysts at $800^{\circ} \mathrm{C}$ leads to Pd-Pt alloy formation. Further, the XAS and LEIS results suggest that the bimetallic nanoparticles expose a Pd-Pt metallic surface enriched in Pd under reducing conditions, while under oxidising conditions a $\mathrm{PdO}$ phase dominates the surface. The samples calcined at lower temperature $\left(500{ }^{\circ} \mathrm{C}\right)$ behave clearly different during the oxidation process. No alloy formation is observed for these samples, indicating that higher temperatures $\left(800{ }^{\circ} \mathrm{C}\right)$ are needed for proper mixing of the two metals. The results show that it is possible to controllably restructure catalysts by use of reactive gas treatment.

\section{Experimental section}

\section{Catalyst preparation and ex situ characterization}

Model catalysts with 2.0 wt.\% Pd and 0.4 wt.\% Pt supported on $\gamma-\mathrm{Al}_{2} \mathrm{O}_{3}$ were prepared by incipient wetness impregnation followed by calcination in either air at $500{ }^{\circ} \mathrm{C}$ for $2 \mathrm{~h}$, in air $800{ }^{\circ} \mathrm{C}$ for $10 \mathrm{~h}$, or in air with addition of $10 \%$ water at $800{ }^{\circ} \mathrm{C}$ for $10 \mathrm{~h}$. For comparison, additional samples containing either $2.0 \mathrm{wt} . \% \mathrm{Pd}$ or $2.0 \mathrm{wt} . \% \mathrm{Pt}$ were prepared. The different samples are summarised in Table 1. For simplicity, the samples will hereafter be referred to by their sample ID.

Several experimental methods, as described below, were employed to study the catalysts.

The size and morphology of the particles for the as-prepared powder catalysts were studied by TEM. Prior to the measurements, the samples were ground in an agate mortar with a few drops of ethanol and then placed on holed carbon film TEM grids. The samples were imaged using a FEI Titan 80-300 microscope with a probe Cs-corrector operated at $300 \mathrm{kV}$ and using a high-angle annular dark-field (HAADF) detector and a scanning TEM imaging mode. The microscope is a field emission gun instrument with a monochromator for 
Table 1: Nomenclature for the catalysts samples used in this study.

\begin{tabular}{cccc}
\hline Sample ID & \multicolumn{2}{c}{ Metal content } & Calcination conditions \\
& $\mathrm{Pd}($ wt.\%) & $\mathrm{Pt}(\mathrm{wt} . \%)$ & \\
\hline Pd-Pt F500 & 2.0 & 0.4 & air @ $500{ }^{\circ} \mathrm{C} 2 \mathrm{~h}$ \\
Pd-Pt F800 & 2.0 & 0.4 & air @ $800{ }^{\circ} \mathrm{C} 10 \mathrm{~h}$ \\
Pd-Pt L800 & 2.0 & 0.4 & air with $10 \% \mathrm{H}_{2} \mathrm{O} @ 800{ }^{\circ} \mathrm{C} 10 \mathrm{~h}$ \\
\hline Pt F500 & - & 2.0 & air @ $500{ }^{\circ} \mathrm{C} 2 \mathrm{~h}$ \\
Pt F800 & - & 2.0 & air @ $800{ }^{\circ} \mathrm{C} 10 \mathrm{~h}$ \\
Pt L800 & - & 2.0 & air with $10 \% \mathrm{H}_{2} \mathrm{O} @ 800{ }^{\circ} \mathrm{C} 10 \mathrm{~h}$ \\
\hline Pd F500 & 2.0 & - & air @ $500{ }^{\circ} \mathrm{C} 2 \mathrm{~h}$ \\
Pd F800 & 2.0 & - & air @ $800{ }^{\circ} \mathrm{C} 10 \mathrm{~h}$ \\
Pd L800 & 2.0 & - & air with $10 \% \mathrm{H}_{2} \mathrm{O} @ 800{ }^{\circ} \mathrm{C} 10 \mathrm{~h}$ \\
\hline \hline
\end{tabular}

high-energy resolution electron energy loss spectroscopy, EELS (0.11 eV resolution), a high resolution energy filter 866 GIF Tridiem mounted on the microscope and an Oxford X-sight energy dispersive spectrometer for energy-dispersive X-ray spectroscopy (EDS).

The crystal structure and alloy formation of the samples was studied by XRD at beamline I711 at MAX IV Laboratory in Lund, Sweden, ${ }^{27,28}$ using a Newport diffractometer equipped with a Pilatus $100 \mathrm{~K}$ area detector, at a fixed wavelength $(\lambda=0.9941 \AA)$. The detector was scanned continuously from 0 to $120^{\circ}$ in approximately 20 min, recording 125 images $/{ }^{\circ}$ (step size of $0.008^{\circ}$ ). The true 2 -theta position of each pixel was recalculated, yielding an average number of 100000 pixels contributing to each 2-Theta value. The samples, contained in 0.3 mm spinning capillaries, were measured in transmission mode.

The surface composition of the Pd-Pt samples was studied by LEIS ${ }^{29}$ at ION-TOF GmbH, Germany using a Qtac $^{100}$ instrument $^{30}$ equipped with a double toroidal energy analyser allowing to achieve high mass resolution and high sensitivity simultaneously. The method provides a quantitative, elemental characterisation of the atomic top layer of the studied sample with spectroscopic, imaging and non-destructive depth profiling capabilities (down to a depth of $10 \mathrm{~nm}$ ). For the spectroscopic measurements, ${ }^{20} \mathrm{Ne}^{+}$ions were used to analyse a $1 \times 1 \mathrm{~mm}^{2}$ area applying a fluence of $1 \mathrm{E}^{13}$ ions $/ \mathrm{cm}^{2}$. Prior to the LEIS measurements, the samples were treated either by atomic oxygen at room temperature for up to 60 min, or 
$50 \mathrm{mbar} \mathrm{H}_{2}$ at $300{ }^{\circ} \mathrm{C}$ for $25 \mathrm{~min}$. In order to remove adsorbed hydrogen after reduction, the samples were monitored during low dose sputtering using He ions from the primary ion beam until steady elemental signals were reached. The reference samples were sputter cleaned with an $1 \mathrm{keV}$ Ar beam and, for the oxidation measurements, they were treated with atomic oxygen as well. Surface roughness correction factors were introduced for the data analysis $\left(\mathrm{R}_{\text {suport }}=0.6, \mathrm{R}_{\text {metallic cluster }}=0.7, \mathrm{R}_{\text {oxidic cluster }}=0.9\right)^{31}$ and the average nanoparticle sizes were calculated by using the surface quantification data of the reduced and oxidised samples assuming a cluster contact angle of $120^{\circ}$ and $90^{\circ}$, respectively. ${ }^{32}$ The diameter is derived from the ratio of the bulk loading (volume) to the LEIS signal (surface area) as described in more detail previously. ${ }^{33}$

CO chemisorption isotherms were measured with ASAP2020 Plus (Micromeritics Instrument Corporation) adsorption volume analyser. Before adsorption measurements the samples were reduced at $300{ }^{\circ} \mathrm{C}$ with $\mathrm{H}_{2}$ for 30 minutes, followed by evacuation for 30 minutes at the same temperature. Adsorption measurements were performed at $25^{\circ} \mathrm{C}$, in the pressure range of 100 to $450 \mathrm{mmHg}$. The chemisorption amounts were determined by extrapolation of the high pressure linear portion of the isotherm to zero pressure. ${ }^{34}$

For the as-prepared samples, ex situ and in situ (see below) XAS measurements were performed at beamline 1811 at MAX IV Laboratory, Lund, Sweden. ${ }^{35,36}$ The Pt $\mathrm{L}_{I I I}$ edge at $11564 \mathrm{eV}$ was measured in fluorescence mode during all measurements due to the low content of Pt (0.4 wt.\%) in the bimetallic samples, using a five-grid ion-chamber Lytle detector (The EXAFS Company). A Pt foil, measured simultaneously with the sample, was used for energy calibration. The XAS measurements included both the X-ray absorption near edge structure (XANES) and Extended X-ray absorption fine structure (EXAFS) regions.

Energy-dispersive (ED) transmission XAS measurements were performed both ex situ and in time-resolved in situ mode with synchronous mass spectrometry (MS), see below, at beamline ID24 at the European Synchrotron Radiation Facility (ESRF) in Grenoble, France. ${ }^{37}$ The measurements were performed using a Si[311] polychromator in Bragg config- 
uration and a FreLoN detector to monitor the Pd K-edge at $24350 \mathrm{eV}$. The experimental set-up included a specially designed reaction cell developed at ID 24 to meet established practice on simultaneous ED-XAS and diffuse reflectance infrared Fourier transformed spectroscopy (DRIFTS) during transient feed of reactants. The cell has a small reactor volume in which a sample cup with diameter $5 \mathrm{~mm}$ and depth $2.5 \mathrm{~mm}$ loaded with about $40 \mathrm{mg}$ of catalyst powder is positioned. The gas composition is controlled by Bronkhorst mass flow controllers and introduced to the cell via air actuated high-speed gas valves (Valco, VICI). All in all facilitating rapid gas composition changes over the catalyst sample.

Energy calibration was performed using a Pd metal foil. After energy calibration the XANES spectra were normalized using the Athena software. ${ }^{38}$ The XAS data were further processed and analysed using Athena and Larch software. ${ }^{39}$ Fourier transformation of the $\mathrm{k}^{2}$ (Pt $\mathrm{L}_{I I I}$ edge) or $\mathrm{k}^{0}$ - (Pd K edge) weighted EXAFS data to the $R$ space was done between

$\mathrm{k}=3$ and $\mathrm{k}=14 \AA^{-1}$ for the Pt $\mathrm{L}_{I I I}$ edge and $\mathrm{k}=3$ and $\mathrm{k}=10 \AA^{-1}$ for the Pd K-edge. Details of the experimental setup and analysis have been described in detail previously. ${ }^{40}$

\section{In situ characterization}

Oxidation and reduction measurements were performed in situ using XAS as described above. For the $\mathrm{Pt}_{\text {III }}$ edge measurements performed at MAX IV Laboratory on the bimetallic samples, the oxidation and reduction measurements were performed at $300{ }^{\circ} \mathrm{C}$ in either $5 \%$ $\mathrm{O}_{2}$ or $5 \% \mathrm{H}_{2}$ using a specially designed reaction cell as described in detail previously. ${ }^{41}$ At ESRF, oxidation/reduction experiments were performed at $360{ }^{\circ} \mathrm{C}$ with alternating pulses of $1.5 \% \mathrm{O}_{2}$ and $2 \% \mathrm{H}_{2}$ (5 min long pulses) by measuring the Pd K edge. The pulses were repeated 3 times to give a total duration of the experiment of 30 min. The introduction of the first $\mathrm{O}_{2}$ pulse triggered the recording of the XAS spectra. He was used as a carrier gas, and the total gas flow was kept constant at $75 \mathrm{~mL} / \mathrm{min}$. 


\section{Results and discussion}

\section{$E x$ situ characterization of as-prepared samples}

The as-prepared catalyst samples were investigated using TEM coupled with EDS, XRD, $\mathrm{XAS}$ and $\mathrm{CO}$ chemisorption.

The TEM analysis for the as-prepared samples provides information about the particle size, the morphology and the distribution of the metals in the catalysts. Fig. 1 (a-c) shows TEM overview images of the as-prepared $\mathrm{Pd}-\mathrm{Pt} / \mathrm{Al}_{2} \mathrm{O}_{3}$ catalysts calcined at either $500{ }^{\circ} \mathrm{C}$ in air (F500), or at $800{ }^{\circ} \mathrm{C}$ in air (F800) or with the addition of $10 \%$ water (L800), where the metal particles appear as lighter on greyish alumina, according to elemental analysis. A detailed analysis of the TEM images obtained for the F500 sample indicates the presence of small particles with different sizes. The EDS area scans on different metal particles for F500 sample (Fig. 1 (a-bottom)) indicates separated Pd and Pt particles. Regions with isolated Pt particles are observed outside the alumina matrix with smaller Pd containing particles embedded in the alumina matrix. No alloy particles have been observed for this sample. For the $\mathrm{Pd}-\mathrm{Pt} / \mathrm{Al}_{2} \mathrm{O}_{3} \mathrm{~F} 800$ sample, the morphology of the catalyst is different as illustrated in Fig. 1 (b). Pt is alloyed with $\mathrm{Pd}$ and the particles are situated mainly in the alumina matrix. EDS area scans on different metal particles for F800 sample confirm the presence of both metals within the individual particles and show that the particles contain an increased proportion of $\mathrm{Pt}$ at the particle edge compared to the centre. For the $\mathrm{Pd}-\mathrm{Pt} / \mathrm{Al}_{2} \mathrm{O}_{3}$ L800 sample, the morphology of the catalyst is slightly different as illustrated in Fig. 1 (c). Particles with similar size, about $50 \mathrm{~nm}$ in diameter, appear to be well dispersed over the alumina support, in contrast to F800 sample where the size of the particles was found to vary between 50 to $100 \mathrm{~nm}$. EDS area scan analysis of several different nanoparticles indicates chemical compositions including both Pd and Pt. Similar to the F800 sample, the EDS

analysis shows that the bimetallic particles contain an increased amount of $\mathrm{Pt}$ at the edge of the particles compared to the centre. In addition, a large number of small Pd nanoparticles 
(about $5 \mathrm{~nm}$ in diameter) can be observed, which are well distributed across the alumina support for both the F800 and L800 samples. It is expected that Pd is more likely to be oxidised to $\mathrm{PdO}$ under the conditions the samples have been treated. ${ }^{42}$

X-ray diffraction patterns were recorded for each of the samples to investigate both the phases present and their crystallinity as well as the mean crystal size of catalyst particles. Fig. 2 shows the XRD patterns from the as-prepared $\mathrm{Pd}-\mathrm{Pt} / \mathrm{Al}_{2} \mathrm{O}_{3}$ catalysts. For comparison the reference patterns from $\mathrm{Pd} / \mathrm{Al}_{2} \mathrm{O}_{3}$ and $\mathrm{Pt} / \mathrm{Al}_{2} \mathrm{O}_{3}$ samples are included. Alumina is observed in the powder XRD patterns for all as-prepared catalysts. The $\mathrm{Pd} / \mathrm{Al}_{2} \mathrm{O}_{3}$ catalysts show the presence of $\mathrm{Al}_{2} \mathrm{O}_{3}$ (denoted by black and green lines at the bottom) and $\mathrm{PdO}$ (denoted by red lines), while the $\mathrm{Pt} / \mathrm{Al}_{2} \mathrm{O}_{3}$ catalysts show the presence of metallic $\mathrm{Pt}$ (denoted by blue lines) in addition to alumina. The different reflections were assigned using the ICSD data for Pd, Pt, PdO and alumina at a wavelength of $0.9941 \AA .{ }^{43}$ The PdO peaks are relatively broad implying that $\mathrm{PdO}$ are highly dispersed over the surface of the support. A clear analysis of the XRD data suggest the support to be a mixture of different alumina phases for all samples, even though the gamma phase dominates the diffraction patterns.

For the F500 samples no peaks due to metallic Pt or Pd are observed, probably due to the relatively low $\mathrm{Pt}$ content and/or high metal dispersion and thus lack of long-range order for these samples. For the $\mathrm{Pd}-\mathrm{Pt} / \mathrm{Al}_{2} \mathrm{O}_{3} \mathrm{~F} 800$ and $\mathrm{L} 800$ samples, additional reflections $\left(\right.$ denoted by ${ }^{*}$ ) characteristic of the $f c c$ crystalline structure of Pt but slightly shifted to higher angles are detected. The new reflections are sharp indicating a bulk structure, rather than a surface strain effect. According to ICSD data the strongest reflections from the (111) and (200) planes of Pt (ICSD data \#41525) and Pd (ICSD data \#41517) shall appear at 25.06 and $29^{\circ}$ for $\mathrm{Pt}$, and 25.5 and $29.53^{\circ}$ for $\mathrm{Pd}$, respectively. In our case we find reflections at 25.25 and $29.25^{\circ}$, i.e. in between the metallic $\mathrm{Pt}$ and $\mathrm{Pd}$ reflections and, therefore, we attribute these to Pd-Pt scattering. From a simple analysis employing Bragg's law for the PdPt reflections, we have calculated a lattice parameter value of $0.391 \mathrm{~nm}$ for Pd-Pt F800 and L800 samples, leading to a Pd-Pt distance of $0.276 \mathrm{~nm}$, which indicates a lattice expansion 
caused by the incorporation of the larger Pt atoms into the $\mathrm{Pd}$ fcc structure $(0.275 \mathrm{~nm})$. These values are in good agreement with previous reports on Pd-Pt alloys. ${ }^{44}$

The full width at half maximum (FWHM) values of the characteristic peaks of $\mathrm{PdO}(101)$ $\left(2 \theta=21.7^{\circ}\right), \operatorname{Pt}(111)\left(2 \theta=25^{\circ}\right)$ and $\mathrm{Pd}-\mathrm{Pt}\left(2 \theta=25.25^{\circ}\right)$ are used to calculate the mean crystallite sizes, using Scherrer's equation, ${ }^{45}$ and the results are listed in Table 2. A shape factor of 0.89 has been used for the calculations. An increase in the $\operatorname{PdO}$ crystallite size by $2.5 \mathrm{~nm}$ is observed for the $\mathrm{Pd}-\mathrm{Pt}$ catalysts compared to $\mathrm{Pd}$ catalysts, while, for the $\mathrm{Pd}-\mathrm{Pt}$ F800 catalyst, less sintering of Pd-Pt crystallites is observed compared to Pt crystallites of Pt monometallic catalysts. Instead for the L800 Pd-Pt sample, the particles seem to have similar sizes as compared to the $\mathrm{Pt} / \mathrm{Al}_{2} \mathrm{O}_{3}$ sample (L800).

Table 2: Mean particle sizes calculated from XRD patterns using Scherrers equation at a wavelength $\lambda=0.9941 \AA$.

\begin{tabular}{cccccccc}
\hline Sample ID & $\begin{array}{c}\mathrm{Pd}: \mathrm{Pt} \\
(\text { wt.\% }\end{array}$ & $\begin{array}{c}2 \theta \mathrm{PdO} \\
\left({ }^{\circ}\right.\end{array}$ & $\begin{array}{c}\mathrm{d}_{P d O} \\
(\mathrm{~nm})\end{array}$ & $\begin{array}{c}2 \theta \mathrm{Pd}-\mathrm{Pt} \\
\left(^{\circ}\right)\end{array}$ & $\begin{array}{c}\mathrm{d}_{P d-P t} \\
(\mathrm{~nm})\end{array}$ & $\begin{array}{c}2 \theta \mathrm{Pt} \\
\left({ }^{\circ}\right)\end{array}$ & $\begin{array}{c}\mathrm{d}_{P t} \\
(\mathrm{~nm})\end{array}$ \\
\hline Pd-Pt F500 & $2: 0.4$ & 21.7 & 7.5 & - & - & - & - \\
Pd-Pt F800 & $2: 0.4$ & 21.7 & 11 & 25.25 & 26 & - & - \\
Pd-Pt L800 & $2: 0.4$ & 21.7 & 10 & 25.25 & 33 & - & - \\
\hline Pt F500 & $0: 2$ & - & - & - & - & - & - \\
Pt F800 & $0: 2$ & - & - & - & - & 25.0 & 32 \\
Pt L800 & $0: 2$ & - & - & - & - & 25.0 & 30 \\
\hline Pd F500 & $2: 0$ & 21.7 & 5 & - & - & - & - \\
Pd F800 & $2: 0$ & 21.7 & 7.5 & - & - & - & - \\
Pd L800 & $2: 0$ & 21.7 & 7.5 & - & - & - & - \\
\hline \hline
\end{tabular}

XRD classically provides information on structures with long range order for phase identification and the estimation of average particle size. Hence, the particle size obtained from the analysis of XRD patterns may not necessary reflect the real particle size, rather it is often overestimated. This may explain the small difference in crystallite size compared to particle sizes observed in our TEM measurements.

Chemisorption of $\mathrm{CO}$ was used to assess the metal dispersion of bi-metallic catalysts since the amount of surface metal atoms can be correlated to the amount of chemisorbed gas. Metal dispersions measured from CO chemisorption uptakes are included in Table 3. Dispersions, 
defined as the fraction of metal $(\mathrm{Pd}, \mathrm{Pt})$ atoms exposed at surfaces, were determined by assuming a CO-to surface metal stoichiometry of 2, implying 1 adsorbed CO molecule per 2 surface metal atoms ${ }^{46}$ (assuming mostly surface $\mathrm{Pd}$ atoms for the reduced samples as will be discussed below). Smaller metal dispersion was obtained for the F800 and L800 samples in comparison to F500 sample, suggesting larger particles, in agreement with the XRD and TEM results presented above. Further, lower particle sizes are calculated from the CO chemisorption, compared to the XRD results. Since chemisorption is sensitive to the outer atoms (where the gas molecules adsorb), smaller particles will highly contribute to the chemisorption values, while $\mathrm{XRD}$ is a bulk sensitive technique, giving an average value of crystallite sizes. Therefore, mostly the smaller monometallic Pd particles in the F800 and L800 Pd-Pt samples will contribute to the chemisorption results. Larger particle sizes may be obtained if one take into consideration that the stoichiometry factor is usually 1 for $\mathrm{Pt}$ and some Pt atoms may be present on the surface of the larger particles for theses samples.

Table 3: Metal dispersions measured from $\mathrm{CO}$ chemisorption uptakes at $25^{\circ} \mathrm{C}$. The metal surface area was calculated from the $\mathrm{H}_{2} / \mathrm{CO}$ uptake by assuming a stoichiometric factor of 2 , meaning $1 / 2 \mathrm{CO}$ molecule was chemisorbed on a metal surface atom. The average crystallite size was calculated from $\mathrm{d}=6 \mathrm{~V} / \mathrm{A}$ assuming a spherical particle diameter, where $\mathrm{V}$ and $\mathrm{A}$ are the total volume and surface area, respectively, of the dispersed material.

\begin{tabular}{cccccc}
\hline Sample ID & $\begin{array}{c}\text { Pd:Pt } \\
(\text { wt.\% })\end{array}$ & $\begin{array}{c}\text { CO uptake } \\
\left(\mathrm{cm}^{3} / \mathrm{g}\right)\end{array}$ & $\begin{array}{c}\text { Metal dispersion } \\
(\%)\end{array}$ & $\begin{array}{c}\text { Metal area } \\
\left(\mathrm{m}^{2} / \mathrm{g}\right)\end{array}$ & $\begin{array}{c}\text { Crystallite sizes } \\
(\mathrm{nm})\end{array}$ \\
\hline Pd-Pt F500 & $2: 0.4$ & 0.025131 & 21.47 & 2.12 & 5.3 \\
Pd-Pt F800 & $2: 0.4$ & 0.014356 & 12.38 & 1.22 & 9.1 \\
Pd-Pt L800 & $2: 0.4$ & 0.014629 & 12.56 & 1.24 & 9 \\
\hline \hline
\end{tabular}

To investigate the chemical state and local structure of the $\mathrm{Pt}$ and $\mathrm{Pd}$ atoms in the as-prepared bimetallic catalysts, XAS data were collected ex situ at the $\mathrm{Pt} \mathrm{L}_{I I I}$ and $\mathrm{Pd} \mathrm{K}$ edges. The XAS results, including both XANES and EXAFS, are displayed in Fig. 3 (Pt $\mathrm{L}_{I I I}$ edge) and Fig. 4 ( $\mathrm{Pd} \mathrm{K}$ edge). The spectra of metallic $\mathrm{Pt}$ and $\mathrm{PtO}_{2}$ are included as a reference. The strong peak above the edge in the XANES spectra is called the white line and is directly related to the density of vacant $d$ orbital states. ${ }^{47,48}$ It corresponds to the $2 \mathrm{p}_{3 / 2}-5 \mathrm{~d}$ transition at the $\mathrm{Pt} \mathrm{L}_{I I I}$ edge and the $1 \mathrm{~s}-4 \mathrm{~d}$ transition at the $\mathrm{Pd} \mathrm{K}$ edge. 
For the F500 sample, the increased white line intensity of the Pt $\mathrm{L}_{I I I}$ edge XANES spectra in Fig. 3 (a) shows that Pt atoms are oxidised. In addition, the higher white line intensity for the F500 sample compared to $\mathrm{PtO}_{2}$ reference foil spectrum may suggest a particle size effect, smaller particles will give an increase in the white line intensity. ${ }^{49,50}$ The features of the $\mathrm{Pt} \mathrm{L}_{I I I}$ edge in the F800 and L800 samples are similar to the Pt foil reference spectrum, which reveals that the state of $\mathrm{Pt}$ in these catalysts is predominantly metallic.

To gain more information about the local structure surrounding the Pt atoms, an EXAFS analysis was performed. Only qualitative evaluation of EXAFS data has been performed in the present study. The Fourier transforms of Pt $\mathrm{L}_{I I I}$ edge EXAFS spectra of the Pd$\mathrm{Pt} / \mathrm{Al}_{2} \mathrm{O}_{3}$ bimetallic catalysts are presented in Fig. 3 (b), where $\mathrm{R}$ represents the radial distance from the absorbing atom. In the Fourier transforms the radial distance $\mathrm{R}$ can be shifted (about 0.2-0.5 $\AA$ ) from the real bond distance due to the phase shift caused by the potentials of the adsorbing and scattering atoms. ${ }^{26,51,52}$ The spectra for the F800 and L800 samples feature a double peak at about 2.2 and $2.7 \AA$ similar to the Pt foil reference spectrum, shifted about $0.1 \AA$ in radial length compared to the Pt foil, indicating the formation of PtPd bonds. The peaks are therefore attributed to Pt-M bond $(\mathrm{M}=\mathrm{Pt}$ or $\mathrm{Pd})$. This is in agreement with both TEM and XRD results presented above, which show alloy formation between Pd and Pt. For the F500 sample the main peak appears at a significantly shorter distance, which can be compared to the shortest Pt-O distance in $\mathrm{PtO}_{2}$. The samples show only the peak associated with the first shell of Pt-O. The absence of a second shell evidences that the sample contains no bulk Pt oxide. In addition, a minor portion of Pt-O bonding is observed at a lower radial length (below $2 \AA$ ) for the F800 and L800 samples, which may be due to some oxygen adsorbed on the surface of the nanoparticles.

In Fig. 4 (a) the normalized XANES spectra for the bimetallic Pd-Pt samples are shown at the Pd K edge. The spectra resemble well the energy dispersive spectrum of PdO reference. ${ }^{40}$ The associated Fourier transforms are shown in Fig. 4 (b). The EXAFS spectra are nearly identical to the EXAFS spectrum of $\mathrm{PdO}$ and the peak below $\mathrm{R}=2 \AA$ is related to the first 
$\mathrm{Pd}-\mathrm{O}$ coordination of $\mathrm{PdO}$, thus indicating the complete oxidation of $\mathrm{Pd}$ in all samples, in agreement with XRD results presented above (Figure 2). No Pd-Pt alloy component can be observed in Pd K edge analysis, due to the increased amount of Pd in the samples and the segregation of $\mathrm{Pd}$ to the surface in an oxidising environment, as discussed below. Therefore, the spectra are dominated by $\mathrm{PdO}$ and the low amount of $\mathrm{PdPt}$ is not observed in $\mathrm{Pd} \mathrm{K}$ edge spectra.

Combining TEM, XRD and XAS results it can be concluded that for the as-prepared bimetallic Pd-Pt model catalysts, Pt exists in either a metallic state (F800 and L800 catalysts), or an oxidised state (F500), while Pd exists in an oxidised state similar to PdO. Alloyed Pd-Pt nanoparticles are formed in the Pd-Pt catalysts only after calcination at 800 ${ }^{\circ} \mathrm{C}$ in presence or absence of water. No alloy formation was observed for the samples calcined at $500{ }^{\circ} \mathrm{C}$, but instead isolated monometallic (Pd and $\mathrm{Pt}$ ) particles.

Our results of alloy formation for the samples calcined at $800{ }^{\circ} \mathrm{C}$ are further supported by our recent DRIFTS results on methane oxidation over the bimetallic catalysts, which show a shift of the CO adsorption band for the F800 and L800 samples compared to F500 sample. ${ }^{53}$

\section{Oxidation and Reduction of bimetallic Pd-Pt samples}

Table 4: The surface area coverage of individual metal components and the cluster size for reduced $\mathrm{Pd}-\mathrm{Pt} / \mathrm{Al}_{2} \mathrm{O}_{3}$ catalysts, determined from ex-situ LEIS measurements and quantified by comparison to the peak areas of the reference Pd and Pt samples. Alloy ${ }_{P d P t}$ means that the cluster size has been calculated assuming alloy particles.

\begin{tabular}{|c|c|c|c|c|c|c|c|c|}
\hline \multirow[t]{2}{*}{ Sample ID } & \multirow{2}{*}{$\begin{array}{l}\text { Pd peak } \\
(\operatorname{cts} / n C)\end{array}$} & \multirow{2}{*}{$\begin{array}{l}\text { Pt peak } \\
(\text { cts } / n C)\end{array}$} & \multirow{2}{*}{$\begin{array}{c}\text { Pd coverage } \\
(\%)\end{array}$} & \multirow{2}{*}{$\begin{array}{c}\text { Pt coverage } \\
(\%)\end{array}$} & \multirow[t]{2}{*}{$\mathrm{Pd} / \mathrm{Pt}$ at. ratio } & \multicolumn{3}{|c|}{ Cluster size } \\
\hline & & & & & & $\begin{array}{l}\text { alloy }_{P d P t} \\
\quad(\mathrm{~nm})\end{array}$ & $\begin{array}{l}\mathrm{Pd} \\
(\mathrm{nm})\end{array}$ & $\begin{array}{c}\mathrm{Pt} \\
(\mathrm{nm})\end{array}$ \\
\hline $\mathrm{Pd}$ & 84062 & - & 100 & - & - & - & - & - \\
\hline $\mathrm{Pt}$ & - & 81252 & - & 100 & - & - & - & - \\
\hline Pd-Pt F500 & 144 & 37 & 0.171 & 0.045 & 3.85 & - & 5 & 2.1 \\
\hline Pd-Pt F800 & 165 & 34 & 0.196 & 0.042 & 4.80 & 4 & - & - \\
\hline Pd-Pt L800 & 136 & 38 & 0.162 & 0.046 & 3.58 & 4.5 & - & - \\
\hline
\end{tabular}

The surface composition of the Pd-Pt bimetallic catalysts was analysed by LEIS. The results are presented in Fig. 5 (a-b) for the reduced and oxidized samples, respectively. The 
Table 5: The surface area coverage of individual metal components and the cluster size for oxidised $\mathrm{Pd}-\mathrm{Pt} / \mathrm{Al}_{2} \mathrm{O}_{3}$ catalysts, determined from ex-situ LEIS measurements and quantified by comparison to the peak areas of the reference Pd and Pt samples. Alloy $P d P t$ means that the cluster size has been calculated assuming alloy particles.

\begin{tabular}{|c|c|c|c|c|c|c|c|c|}
\hline \multirow[t]{2}{*}{ Sample ID } & \multirow{2}{*}{$\begin{array}{l}\text { Pd peak } \\
\text { (cts } / \mathrm{nC})\end{array}$} & \multirow{2}{*}{$\begin{array}{l}\text { Pt peak } \\
(\operatorname{cts} / n C)\end{array}$} & \multirow{2}{*}{$\begin{array}{c}\text { Pd coverage } \\
(\%)\end{array}$} & \multirow{2}{*}{$\begin{array}{c}\text { Pt coverage } \\
(\%)\end{array}$} & \multirow[t]{2}{*}{$\mathrm{Pd} / \mathrm{Pt}$ at. ratio } & \multicolumn{3}{|c|}{ Cluster size } \\
\hline & & & & & & $\begin{array}{l}\text { alloy }_{P d P t} \\
\quad(\mathrm{~nm})\end{array}$ & $\begin{array}{l}\mathrm{PdO} \\
(\mathrm{nm})\end{array}$ & $\begin{array}{c}\mathrm{PtO}_{2} \\
(\mathrm{~nm})\end{array}$ \\
\hline $\mathrm{Pd}$ & 15731 & - & 100 & - & - & - & - & - \\
\hline $\mathrm{Pt}$ & - & 11735 & - & 100 & - & - & - & - \\
\hline Pd-Pt F500 & 32 & 27 & 0.203 & 0.230 & 1.29 & - & 12.5 & 2.1 \\
\hline Pd-Pt F800 & 63 & 4 & 0.400 & 0.034 & 17.15 & 4.6 & - & - \\
\hline Pd-Pt L800 & 60 & 4 & 0.381 & 0.034 & 16.34 & 4.8 & - & - \\
\hline
\end{tabular}

surface area coverage of $\mathrm{Pd}$ and $\mathrm{Pt}$ can be quantified by comparison to the peak areas of the reference samples and are presented in Table 4 and Table 5. The results show that a $\mathrm{Pd}-\mathrm{Pt}$ (Pd dominated) surface is exposed under reducing conditions, while under oxidising conditions $\mathrm{Pd}$ is oxidised and forms $\mathrm{PdO}^{42}$ that dominates the surface. During reduction conditions, there is an enrichment of Pt at the surface of the bimetallic nanoparticles compared to the bulk, but still less Pt compared to Pd due to increased molar ratio of Pd in the samples $(\mathrm{Pd}: \mathrm{Pt}=5: 1)$. In contrast to oxidised F800 and L800 samples, which show an enhanced Pd surface segregation, the oxidised F500 sample shows a similar amount of Pd and $\mathrm{Pt}$ at the surface of the nanoparticles.

The average cluster sizes were calculated using the surface quantification data of the reduced and oxidised samples, as shown in Table 4 and Table 5, respectively. Given the surface area of the support and the $\mathrm{Pd} / \mathrm{Pt}$ loading, the average cluster size can be calculated from the $\mathrm{Pd} / \mathrm{Pt}$ surface coverage, using the method described in Ref. ${ }^{54}$ This results in a cluster size of approximately $4.6 \mathrm{~nm}$ for the alloy nanoparticles, determined from the oxidised samples data.

The information obtained from LEIS measurements is very complementary to XRD and TEM measurements. Since LEIS detects the surface atoms (precisely the atoms that determine surface chemistry) it is consequently more sensitive to the smaller nanoparticles, while XRD and TEM are more sensitive to larger particles (30-50 nm). For the oxidised 
F500 sample, an increase in the PdO nanoparticle size compared to the reduced sample is calculated from the LEIS data, which may explain the similar Pd:Pt ratio for this sample. LEIS contributes in determining the concentration of $\mathrm{Pd}$ and $\mathrm{Pt}$ in the outer surface as well as the average diameter of the nanoparticles without discrimination of the very small particles. Previous LEIS work has shown that if there is a very narrow size distribution of the nanoparticles, LEIS gives closely the same size as techniques such as TEM, or XRD. For wide distributions, however, TEM will give a heavier weight to the larger particles, while LEIS sees the smaller particles (more surface atoms for the same amount of Pd, Pt) better. In this study the results between LEIS and TEM, XRD are rather different, which suggests a rather wide particle distribution. Similar particle sizes are determined from chemisorption and LEIS experiments, since both techniques are sensitive to the surface atoms. One should take into account for the metal coverage that chemisorption will occur at all free sides of the nanoparticles, while LEIS only sees the side of the nanoparticles that is exposed to the beam, leading to small differences between the two methods.

Transient oxidation and reduction of all bimetallic samples was studied by in situ energydispersive XAS and the white line intensity was used to follow the oxidation and reduction of Pd. Fig. 6 (a-c) shows the evolution of the XAFS spectra for the Pd-Pt F500 sample at $360{ }^{\circ} \mathrm{C}$ during the oxidation-reduction cycling experiment in either $1.5 \% \mathrm{O}_{2}$ or $2 \% \mathrm{H}_{2}$. The experiment starts with a 5 min oxidation pulse. The left panel (a) shows XAS spectra recorded at the end of the oxidation and reduction periods, while the right panel shows the recorded XAS spectra as a function of time (b) together with the white line intensity during the experiment (c). The XAS spectra in the left panel are clearly different when they are recorded at the end of an oxidation period compared to the end of a reduction period, and the spectra recorded at different oxidation or reduction periods are very similar to one another. The spectra recorded during the end of the reduction and oxidation periods are similar to the spectra of $\mathrm{Pd}$ foil and $\mathrm{PdO}$ powder, respectively as reported in our previous contribution. ${ }^{40}$ 
The EXAFS analysis (Figure S1, Supplementary Information) indicates that, during oxidation, the $\mathrm{Pd}$ atoms are in an oxidised state similar to $\mathrm{PdO}$, but under reducing conditions the $\mathrm{PdO}$ phase is reduced to a metallic Pd state. No contribution from Pd-metal scattering at oxidising conditions could be observed indicating that Pd is fully oxidised.

Similar results were obtained for the F800 and L800 samples and detailed results are presented in the Supporting Information (Figure S2 and Figure S3). Fig. 7 shows the evolution of the white line intensity of the Pd K edge as a function of time during periodic cycling between oxidising and reducing periods over all investigated Pd-Pt samples. An increase in the white line intensity is observed for the F800 and L800 samples compared to F500 sample, even during the reduction periods, and may be explained by the alloy formation between $\mathrm{Pd}$ and $\mathrm{Pt}$, as previously reported. ${ }^{51,55} \mathrm{In}$ this process, the electron transfer from the adjacent Pd atoms will lead to a partial filling of the unoccupied Pt 5d orbitals, which can also be interpreted from the electronegativity difference of Pd and Pt elements with 2.20 and 2.28, respectively. Further, the lower white line intensity during the oxidation periods for the L800 sample compared to F800 sample may be due to a particle size effect. ${ }^{56}$ Larger particles will give a decrease in the white line intensity since the oxidised Pd on the surface represents a relatively smaller proportion of the total number of Pd in the particles.

It is interesting to note that the white line intensity decreases quite fast at the start of the reduction period, which indicates a fast full reduction of the Pd-Pt nanoparticles. In addition, a Pd-Pd type of bond could be determined from the EXAFS analysis for all Pd-Pt reduced samples, suggestive of a segregated Pd phase (see Figure S1, Supporting Information).

A similar oxidation/reduction experiment was performed by recording the $\mathrm{Pt} \mathrm{L}_{I I I}$ edge under $5 \% \mathrm{O}_{2}$ or $5 \% \mathrm{H}_{2}$ treatments at $300{ }^{\circ} \mathrm{C}$ for 20 minutes. Fig. 8 (a-d) displays the $\mathrm{Pt} \mathrm{L}_{I I I}$ edge XANES and EXAFS spectra of both the reduced and oxidised catalysts. The XANES spectra from the reduced samples are very similar to $\mathrm{Pt}$ foil spectrum suggesting that $\mathrm{Pt}$ is in a metallic state for all reduced samples. For the oxidised samples, the F500 sample shows 
an increased white line intensity indicating that $\mathrm{Pt}$ is in an oxidised state, in contrast to the F800 and L800 samples spectra which are similar to the Pt foil spectrum. These results indicate that the Pt atoms dispersed on the alumina support and calcined at $500{ }^{\circ} \mathrm{C}$ have a higher affinity towards oxygen leading to higher oxidation states of Pt, similar to the results obtained on the as-prepared samples and discussed above. In fact, it is known that small Pt particles tend to be easily oxidised. ${ }^{57,58}$ The increased white line intensity for the F500 sample may indicate that all $\mathrm{Pt}$ is oxidised which in turn may suggest smaller particles, as observed for the as-prepared samples.

The associated Fourier transforms are shown in Fig. 8 (b) and (d). The EXAFS spectra recorded from the reduced samples feature a double peak at radial distances between 2 and $3 \AA$, which is attributed to metal-metal scattering. For the F500 sample the position of the peaks are close to the peaks for the Pt foil, suggesting a Pt-Pt type of bond, while for the F800 and L800 samples the peaks are slightly shifted towards longer radial distances suggesting a $\mathrm{Pt}-\mathrm{M}$ bond type $(\mathrm{M}=\mathrm{Pd}$ or $\mathrm{Pt})$. The EXAFS analysis from the oxidised samples shows a similar behaviour to the as-prepared samples discussed above. The F800 and L800 samples show that Pt is mostly in a metallic state, while the F500 sample shows an oxide coordination below $2 \AA$ suggesting a Pt-O type of bond.

Comparing Fig. 8 (b) and (d) it can be observed that, except the small oxide component (most probably due to some chemisorbed oxygen), there is no structural difference of the $\mathrm{Pt}$ atoms after reduction and oxidation of the F800 and L800 catalysts and the Pt atoms are in a reduced metallic state.

\section{Conceptual interpretation of the oxidation/reduction behaviour}

Combining XAS and LEIS measurements for the oxidised and reduced Pd-Pt catalysts, some conclusions can be drawn as discussed below.

Based on the EXAFS analysis, there is evidence of alloy formation between Pd and Pt on the samples calcined at $800{ }^{\circ} \mathrm{C}$, as supported by the TEM and XRD results obtained for the 
as-prepared catalysts. The XAS data show that the nanoparticles are oxidised when exposed to $\mathrm{O}_{2}$, forming a PdO-like phase, and reduced back to a reduced (metallic) state when $\mathrm{O}_{2}$ is removed and $\mathrm{H}_{2}$ is introduced to the feed. In contrast, during oxidation treatment, both $\mathrm{PdO}$ and $\mathrm{PtO}_{2}$ are found to form on the Pd-Pt F500 sample, with no alloy formation between $\mathrm{Pd}$ and Pt. If mixed PtPd oxide will form on the F800 and L800 samples, we would expect to observe also oxidised $\mathrm{Pt}$ in addition to $\mathrm{PdO}$ during the oxidising conditions, in contrast to the EXAFS analysis of $\mathrm{Pt} \mathrm{L}_{I I I}$ edge that clearly shows only a metallic state of Pt. For the F500 sample, if a mixed PtPd oxide would form, one would expect that both Pt and Pd will be in an oxidized state in EXAFS analysis during oxidation, which is indeed the case in our study. However, if F500 sample would contain mixed nanoparticles, we would expect to see the evidence of alloy formation during reduction, i.e. Pt-Pd bonds, and not a separation of the Pd and Pt, where both Pd and Pt have only Pd and Pt neighbors, respectively. Thus, we do exclude the formation of mixed PtPd oxide on all samples. This observation is also supported by DFT calculations. According to Dianat et al. ${ }^{59}$ mixed oxides of $\mathrm{PtO}_{2}$ and $\mathrm{PdO}$ are only stable below $200{ }^{\circ} \mathrm{C}$ (@ 1 atm air). It is thus understandable that there are no mixed particles for $\mathrm{F} 500$. The melting point of $\mathrm{PtO}_{2}$ is $450{ }^{\circ} \mathrm{C}$, so at $500{ }^{\circ} \mathrm{C}$ it will be very mobile. Thus it will disperse on alumina or form $\mathrm{PtO}_{2}$ particles, in agreement with XAS results presented above. Around $800{ }^{\circ} \mathrm{C}$ (@ 1 atm air) $\mathrm{PdO}$ starts decomposing and forming particles as previously reported. ${ }^{60}$

Since Pt $\mathrm{L}_{I I I}$ edge EXAFS analysis resolves a Pt-Pd interaction for both the F800 and L800 catalysts, while analysis of the Pd K edge resolves mostly Pd-O bonds, it is suggested that there are both Pd regions and regions with Pd-Pt mixing on the surface of the catalysts. A possible explanation to why no Pd-Pt bond can be observed in the Pd K edge from the alloy nanoparticles is the increased amount of $\mathrm{Pd}$ in the samples (Pd:Pt ratio 1:5; one $\mathrm{Pt}$ atom is surrounded by some $\mathrm{Pd}$ atoms, while one $\mathrm{Pd}$ atom is surrounded by only one $\mathrm{Pt}$ atom and several Pd atoms). Oxygen treatment promotes Pd segregation to the surface of the Pd-Pt nanoparticles and formation of $\mathrm{PdO}$, while the nanoparticles expose metallic $\mathrm{Pd}$ 
and some regions with $\mathrm{Pd}-\mathrm{Pt}$ mixing after reductive treatment as previously reported in the literature. ${ }^{26}$

An illustrative model of the oxidation and reduction behaviour of Pd-Pt catalysts studied in the present work is shown in Fig. 9. It shall be noted that the particle shape is only illustrative in this Figure, at this moment we do not have enough data to determine the exact particle shape, and, as given by the in situ oxidation/reduction treatment (Figure 6), a change in the particle shape is most likely to occur which can explain the different kinetics (slow oxidation/ fast reduction).

\section{Conclusions}

Surface structure and oxidation/reduction behaviour of supported Pd-Pt catalysts have been studied using a combination of TEM, XRD, XAS, LEIS and CO chemisorption. The results show that bimetallic Pd-Pt nanoparticles were only formed on the Pd-Pt catalysts after calcination at $800{ }^{\circ} \mathrm{C}$. In addition to alloy nanoparticles, theses samples show the presence of smaller Pd nanoparticles. The restructuring behaviour is different for the bimetallic Pd-Pt nanoparticles. The results suggest that a Pd-Pt metallic surface (Pd enriched) is exposed under reducing conditions, while under oxidising conditions a $\mathrm{PdO}$ phase dominates the surface. The Pd-Pt sample calcined at lower temperature $\left(500{ }^{\circ} \mathrm{C}\right)$ shows the presence of isolated monometallic nanoparticles with no indication of alloy formation. Higher temperature is needed for a proper alloying of $\mathrm{Pd}$ and $\mathrm{Pt}$. The results show that it is possible to controllably restructure catalysts with the use of reactive gases.

\section{Supporting Information Available}

Figures S1-S3: XANES and EXAFS analysis of Pd K edge during oxydation/reduction cycling experiment at $360{ }^{\circ} \mathrm{C}$. This material is available free of charge via the Internet at http://pubs.acs.org/. 


\section{Acknowledgement}

Dr. Stefan Gustafsson is thanked for his assistance with the TEM characterisation. The authors thank MAX IV Laboratory (Lund, Sweden) and the European Synchrotron Radiation Facility (ESRF) (Grenoble, France) for providing the beamtimes. This work was financially supported by the Swedish Research Council through the Röntgen-Ångström collaborations "Catalysis on the atomic scale" (No. 349-2011-6491) and "Time-resolved in situ methods for design of catalytic sites within sustainable chemistry" (No. 349-2013-567) and the Swedish Energy Agency through the FFI program "Fundamental studies on the influence of water on oxidation catalyst for biogas applications" (No. 40274-1), and partly the Competence Centre for Catalysis, which is financially supported by Chalmers University of Technology, the Swedish Energy Agency and the member companies: AB Volvo, ECAPS AB, Haldor Topsøe A/S, Volvo Car Corporation, Scania CV AB, and Wärtsilä Finland Oy.

\section{References}

(1) Somorjai, G. A. Introduction to Surface Chemistry and Catalysis, Wiley-VCH: New York, 1994 .

(2) Burda, C.; Chen, X.B.; Narayanan, R.; El-Sayed, M.A. Chemistry and Properties of Nanocrystals of Different Shapes. Chem. Rev. 2005, 105, 1025-1102.

(3) Campbell, C.T. Bimetallic Surface Chemistry. Annu. Rev. Phys. Chem. 1990, 41, 775837.

(4) Rodriguez, J.A.; Goodman, D.W. The Nature of the Metal-Metal Bond in Bimetallic Surfaces. Science 1992, 257, 897-903.

(5) Stamenkovic, V.R.; Fowler, B.; Mun, B.S.; Wang, G.; Ross, P.N.; Lucas, C.A.; Markovic, N.M. Improved Oxygen Reduction Activity on Pt3Ni(111) via Increased Surface Site Availability. Science 2007, 315, 493-497. 
(6) Zhou, S.; Varughese, B.; Eichhorn, B.; Jackson, G.; McIlwrath, K. Heterogeneous Catalysis Pt-Cu Core-Shell and Alloy Nanoparticles for Heterogeneous NOx Reduction: Anomalous Stability and Reactivity of a Core-Shell Nanostructure. Angew. Chem., Int. Ed. 2005, 44, 4539-4543.

(7) Murillo, L.E.; Goda, A.M.; Chen, J.G. Selective Hydrogenation of the CO Bond in Acrolein Through the Architecture of Bimetallic Surface Structures. J. Am. Chem. Soc. 2007, 129, 7101-7105.

(8) Enache, D.I.; Edwards, J.K.; Landon, P.; Solsona-Espriu, B.; Carley, A.F.; Herzing, A. A.; Watanabe, M.; Kiely, C.J.; Knight, D.W.; Hutchings, G.J. Solvent-Free Oxidation of Primary Alcohols to Aldehydes Using Au-Pd/TiO2 Catalysts. Science 2006, 311, 362-365.

(9) Bligaard, T.; Nørskov, J.K.; Rossmeisl, J.; Christensen, C.H. Towards the Computational Design of Solid Catalysts. Nat. Chem. 2009, 1, 37-46.

(10) Nørskov, J.K.; Christensen, C.H. Toward Efficient Hydrogen Production at Surfaces. Science 2006, 312 1322-1323.

(11) Besenbacher, F.; Chorkendorff, I.; Clausen, B.S.; Hammer, B.; Molenbroek, A.M.; Nørskov, J.K.; Stensgaard, I. Design of a Surface Alloy Catalyst for Steam Reforming. Science 1998, 279, 1913-1915.

(12) Johnson, W.C.; Blakely, J.M. Eds. Interfacial Segregation; American Society for Metals: Metals Park, OH, 1979.

(13) Chelikowsky, J.R. Predictions for Surface Segregation in 2.550 Binary Intermetallic Alloys; Research Report; Exxon Research and Engineering Co.: Linden, NJ.

(14) Du Plessis, J. Surface Segregation; Solid State Phenomena; Sci-Tech Publications: Vaduz, Liechtenstein, 1990, Vol. 11. 
(15) Tao, F. et al. Reaction-Driven Restructuring of Rh-Pd and Pt-Pd Core-Shell Nanoparticles. Science 2008, 322, 932-934.

(16) Narui, K.; Yata, H.; Furata, K.; Nishida, A.; Kohtoku, Y.; Matsuzaki, T. Effects of Addition of $\mathrm{Pt}$ to $\mathrm{PdO} / \mathrm{Al} 2 \mathrm{O} 3$ Catalyst on Catalytic Activity for Methane Combustion and TEM Observations of Supported Particles. Appl. Catal. A: General 1999, 179, 165-173.

(17) Lapisardi, G.; Urfels, L.; Gelin, P.; Primet, M.; Kaddouri, A.; Garbowski, E.; Toppi, S.; Tena, E. Superior Catalytic Behaviour of Pt-Doped Pd Catalysts in the Complete Oxidation of Methane at Low Temperature. Catal.Today 2006, 117, 564-568.

(18) Strobel, R.; Grunwaldt, J.-D.; Camenzind, A.; Pratsinis, S. E.; Baiker, A. Flame-Made Alumina Supported Pd-Pt Nanoparticles: Structural Properties and Catalytic Behavior in Methane Combustion. Catal. Lett. 2005, 104, 9-16.

(19) Persson, K.; Ersson, A.; Jansson, K.; Fierro, J.L.G.; Järås, S. G. Influence of Molar Ratio on Pd-Pt Catalysts for Methane Combustion. J. Catal. 2006, 243, 14-24.

(20) Chen, M.; Schmidt, L.D. Morphology and Composition of PtPd Alloy Crystallites on $\mathrm{SiO} 2$ in Reactive Atmospheres. J. Catal. 1979, 56, 198-218.

(21) Guczi, L.; Karpinski, Z. Catalytic Reactions of Hydrocarbons Over Pt-Pd Alloys: II. Deuterium Exchange of Methane and Ethane Over Pt-Pd Alloy Films. Surface Composition of Pt-Pd Alloy System. J. Catal. 1979, 56, 438-444.

(22) Harada, M.; Asakura, K.; Ueki, Y.; Toshima, N. Structure of Polymer-Protected Palladium-Platinum Bimetallic Clusters at the Oxidized State: Extended X-ray Absorption Fine Structure Analysis. J. Phys. Chem. 1992, 96, 9730-9738.

(23) Hansen, P.L.; Molenbroek, A.M.; Ruban, A.V. Alloy Formation and Surface Segregation 
in Zeolite-Supported Pd-Pt Bimetallic Catalysts. J. Phys. Chem. B 1997, 101, 18611868.

(24) Van den Oetelaar, L. C. A.; Nooij, O. W.; Oerlemans, S.; Denier van der Gon, A. W.; Brongersma, H.H.; Lefferts, L.; Roosenbrand, A. G.; van Veen, J. A. R. Surface Segregation in Supported Pd-Pt Nanoclusters and Alloys. J. Phys.. Chem. B 1998, 102, 3445-3455.

(25) Persson, K.; Jansson, K.; Järås, S. Charecterisation and Microstructure of Pd and Bimetallic Pd-Pt Catalysts During Methane Oxidation. J. Catal. 2007, 254, 401-414.

(26) Morlang, A.; Neuhausen, U.; Klementiev, K. V.; Schütze, F.-W.; Miehe, G.; Fuess,H.; Lox, E.S. Bimetallic Pt/Pd Diesel Oxidation Catalysts: Structural Characterisation and Catalytic Behaviour. Appl. Catal. B: Environ. 2005, 60, 191-199.

(27) Cerenius, Y. ; Ståhl, K.; Svensson, L.A.; Ursby, T.; Oskarsson, Å.; Albertsson, J.; Liljas, A. The Crystallography Beamline I711 at MAX II. J. Synchrotron Rad. 2000, 7, 203-208.

(28) Knaapila, M. et al. A New Small-Angle X-ray Scattering Set-up on the Crystallography Beamline I711 at MAX-lab. J. Synchrotron Rad. 2009, 16, 498-504.

(29) Brongersma, H.H. Low-Energy Ion Scattering in: Characterization of Materials; Ed. Elton N. Kaufmann, J. Wiley \& Sons, 2012.

(30) https://www.iontof.com

(31) Jansen, W.P.A.; Knoester, A.; Maas, A.J.H.; Schmitt, P.; Kytokivi, A.; Denier van der Gon, A.W.; Brongersma, H.H. The Influence of Compaction and Surface Roughness on Low-energy Ion Scattering Signals. Surf. Interf. Anal. 2004, 36, 1469-1478.

(32) Ter Veen, H.R.J.; Kim, T.; Wachs, I.E.; Brongersma, H.H. Applications of High 
Sensitivity-Low Energy Ion Scattering (HS-LEIS) in Heterogeneous Catalysis. Catal. Today 2009, 140, 197-201.

(33) Jansen; W.P.A.; Harmsen, J.M.A.; Denier v.d. Gon, A.W.; Hoebink, J.H.B.J.; Schouten, J.C.; Brongersma, H.H. Noble Metal Segregation and Cluster Size of $\mathrm{Pt} / \mathrm{Rh} / \mathrm{CeO} 2 / \gamma \mathrm{Al} 2 \mathrm{O} 3$ Automotive Three-Way Catalysts Studied with Low-Energy Ion Scattering. J. Catal. 2001, 204, 420-427.

(34) Anderson, J.R.; Pratt, K.C. Introduction to Characterization and Testing of Catalysts; Academic Press, Sydney, 1985.

(35) Grehk, T.M.; Nilsson, P.O. The Design of the Material Science Beamline, I811 at MAX II. Nucl. Instr. and Meth. in Phys. Res. A 2001, 635, 467-468.

(36) Carlson, S; Clausen, M.; Gridneva, L.; Sommarin, B.; Svensson, C. XAFS Experiments at Beamline I811, MAX-Lab Synchrotron Source, Sweden. J. Synchrotron. Rad. 2006, $13,359-364$.

(37) Pascarelli, S. et al. Dispersive XAS at Third-Generation Sources: Strengths and Limitations. J. Synchrotron Rad. 1999, 6, 146-148.

(38) Ravel, B.; Newville, M. ATHENA, ARTEMIS, HEPHAESTUS: Data Analysis for Xray Absorption Spectroscopy Using IFEFFIT. Journal of Synchrotron Radiation 2005, 12, 537-541.

(39) Newville, M. Larch: An Analysis Package for XAFS and Related Spectroscopies. J. Phys.: Conf. Ser. 2013, 430, 012007-012014.

(40) Nilsson, J.; Carlsson, J.; Fouladvand, S.; Martin, N. M.; Gustafson, J.; Newton, M. A.; Lundgren, E.; Grönbeck, H.; Skoglundh, M. Chemistry of Supported Palladium Nanoparticles During Methane Oxidation. ACS Catal. 2015, 5, 2481-2489. 
(41) Zhang, C.; Gustafson, J.; Merte, L. R.; Evertsson, J.; Noren, K.; Carlson, S.; Svensson, H.; Carlsson, P.-A. An in Situ Sample Environment Reaction Cell for Spatially Resolved X-ray Absorption Spectroscopy Studies of Powders and Small Structured Reactors. Rev. Sci. Instr. 2015, 86, 033112-1:7.

(42) Mallika, C.; Sreedharan, O. M.; Gnanamoorthy, J. B. Determination of the Standard Free-Energy of Formation of $\mathrm{PDO}(\mathrm{s})$ from the Solid Oxide Electrolyte EMF. J. LessCommon Met. 1983, 95, 213-220.

(43) https://icsd.fiz-karlsruhe.de (accessed January 2016)

(44) Li, X.; Zhu, Y.; Zou, Z.; Zhao, M.; Li, Z.; Zhou, Q.; Akins, D.A.; Yang, H. Simple Complexing-Reduction Synthesis of Pd-Pt/C Alloy Electrocatalysts for the Oxygen Reduction Reaction. J. Electrochem. Soc. 2009, 156(10), B1107-B1111.

(45) Radmilovic, V.; Gasteiger, H. A.; Ross Jr, P. N.; Structure and Chemical Composition of a Supported Pt-Ru Electrocatalysis for Methanol Oxidation. J. Catal. 1995, 154, 98-106.

(46) Canton, P.; Fagherazzi, G.; Battagliarin, M.; Menegazzo, F.; Pinna, F.; Pernicone, N. $\mathrm{Pd} / \mathrm{CO}$ Average Chemisorption Stoichiometry in Highly Dispersed Supported $\mathrm{Pd} / \gamma$ Al2O3 Catalysts. Langmuir 2002, 18, 6530-6535.

(47) Sham, T. K. L-Edge X-ray-absorption Systematics of the Noble Metals Rh, Pd, and Ag and the Main-group Metals In and Sn: A Study of the Unoccupied Density of States in 4d Elements. Phys. Rev. B: Condens. Matter Phys. 1985, 31, 1888-1902.

(48) Kim, H. J.; Choi, S. M.; Nam, S. H.; Seo, M. H.; Kim, W. B. Effect of Rh Content on Carbon-Supported PtRh Catalysts for Dehydrogenative Electrooxidation of Cyclohexane to Benzene Over Polymer Electrolyte Membrane Fuel Cell. Appl. Catal. A 2009, 352, 145-151. 
(49) Bazin, D.; Sayers, D.; Rehr, J. J.; Mottet, C. Numerical Simulation of the Platinum LIII Edge White Line Relative to Nanometer Scale Clusters. J. Phys. Chem. B 1997, 101, 5332- 5336 .

(50) Bazin, D.C.; Sayers, D. A.; Rehr, J. J. Comparison Between X-ray Absorption Spectroscopy, Anomalous Wide Angle X-ray Scattering, Anomalous Small Angle X-ray Scattering, and Diffraction Anomalous Fine Structure Techniques Applied to NanometerScale Metallic Clusters. J. Phys. Chem. B 1997, 101, 11040- 11050.

(51) Chang, S.-H.; Su,W.N.; Yeh, M.H.; Pan, C.J.; Yu, K.L.; Liu, D.G.; Lee, J. F.; Hwang, B. J. Structural and Electronic Effects of Carbon-Supported PtxPd1-x Nanoparticles on the Electrocatalytic Activity of the Oxygen-Reduction Reaction and on Methanol Tolerance. Chem. -Eur. J. 2010, 16, 11064-11071.

(52) Matsui, T.; Harada, M.; Bando, K.K.; Toba, M.; Yoshimura, Y. EXAFS Study on the Sulfidation Behavior of Pd, Pt and Pd-Pt Catalysts Supported on Amorphous Silica and High-Silica USY Zeolite. Appl. Catal. A. 2005, 290, 73-80.

(53) N.M. Martin et al. Study of Methane Oxidation Over Alumina Supported Pd-Pt Catalysts Using in Situ DRIFTS and XAS Techniques. Submitted to Catalysis, Structure and Reactivity (2016).

(54) Tanabe, T. et al. Low Temperature CO Pulse Adsorption for the Determination of Pt Particle Size in a Pt/Cerium-Based Oxide Catalyst. Appl. Catal. A: General 2009, 370, 108-113.

(55) Kim, Y.; Noh, Y.; Lim, E.J.; Lee, S.; Choid, S.M.; Kim, W.B. Star-Shaped Pd@Pt Core-Shell Catalysts Supported on Reduced Graphene Oxide with Superior Electrocatalytic Performance. J. Mater. Chem. A 2014, 2, 6976-6986.

(56) Antolini, E.; Zignani, S.C.; Santos, S.F.; Gonzalez, E.R. Pd-Based Electrodes: A Way 
to Reduce Pt Content in Polymer Electrolyte Membrane Fuel Cells. Electrochim. Acta 2011, 56, 2299-2305.

(57) Tang, Y.; Zhang, L.; Wang, Y.; Zhou, Y.; Gao, Y.; Liu, C.; Xing, W.; Lu, T. Preparation of a Carbon Supported Pt Catalyst Using an Improved Organic Sol Method and its Electrocatalytic Activity for Methanol Oxidation. J. Power Sources 2006, 162, $124-131$.

(58) Douidah, A.; Marécot, P.; Szabo, S.; Barbier, J. Evaluation of the Metal-Support Interactions Case of Platinum-Supported Catalysts: Effect of the Support Nature and the Metallic Dispersion. Appl. Catal. A 2002, 225, 21-31.

(59) Dianat, A.; Seriani, N.; Bobeth, M.; Pompe, W.; Colombi Ciacchi, L. DFT Study of the Thermodynamic Stability of Pd-Pt Bulk Oxide Phases. J. Phys. Chem. C 2008, 112, 13623-13628.

(60) Farrauto, R.J.; Hobson, M.C.; Kennelly, T.; Waterman, E.M. Catalytic Chemistry of Supported Palladium for Combustion of Methane. Applied Catalysis A: General 1992, $81,227-237$. 

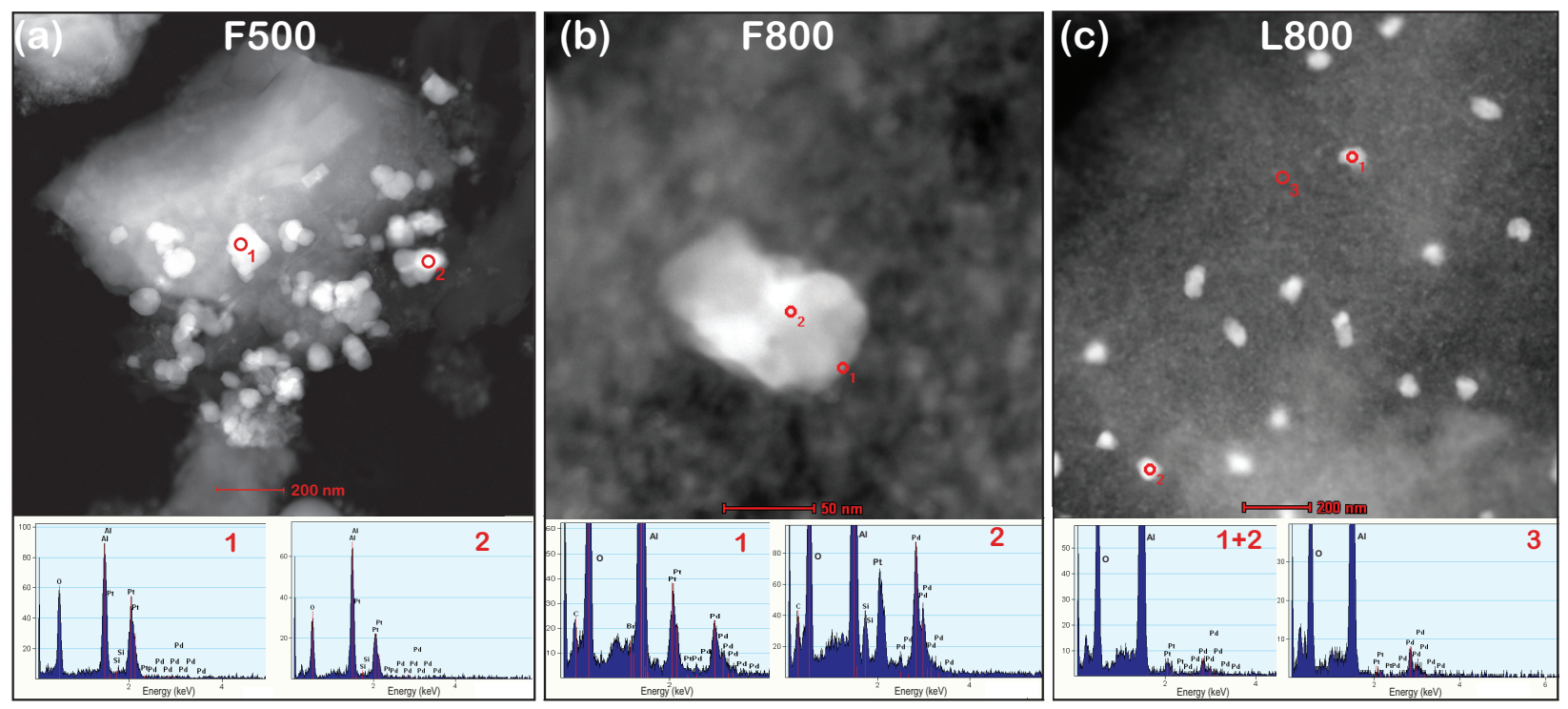

Figure 1: Representative TEM images of the as-prepared Pd-Pt bimetallic (a) F500, (b) F800 and (c) L800 samples. EDS analysis of the different areas denoted by red $\circ$ are shown on the bottom of the corresponding TEM image. 


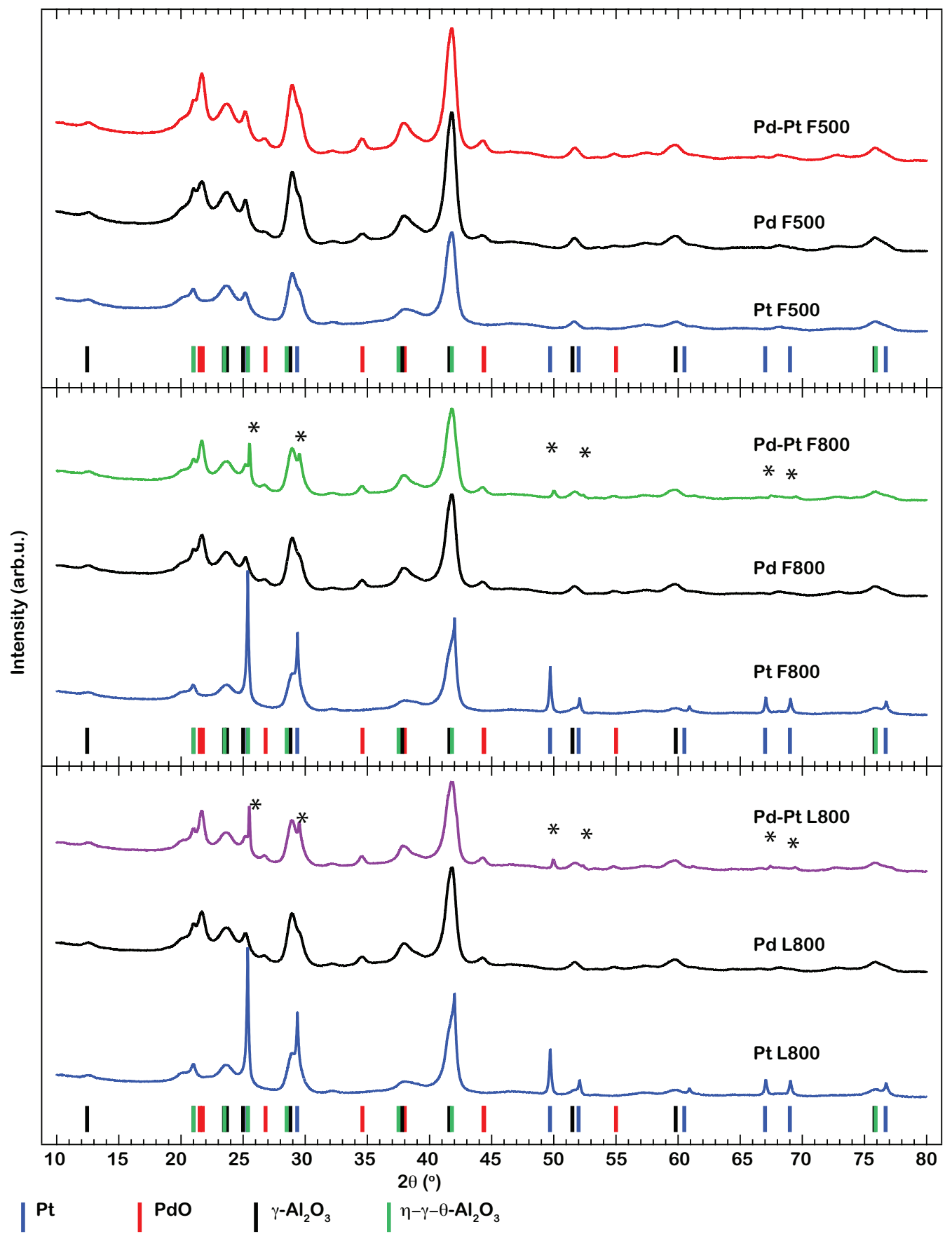

Figure 2: XRD patterns of as-prepared $\mathrm{Pd}-\mathrm{Pt} / \mathrm{Al}_{2} \mathrm{O}_{3}$ catalysts calcined at different temperatures (red). The XRD patterns from 2 wt. $\% \mathrm{Pd} / \mathrm{Al}_{2} \mathrm{O}_{3}$ (black) and 2 wt. $\% \mathrm{Pt} / \mathrm{Al}_{2} \mathrm{O}_{3}$ (blue) samples are included as references. The coloured bars at the bottom represent the reflections calculated using the ICSD database for Pt (blue), $\mathrm{PdO}$ (red), and alumina (black- $\gamma$ phase and green- combination of $\eta-\gamma-\theta$ phases). 

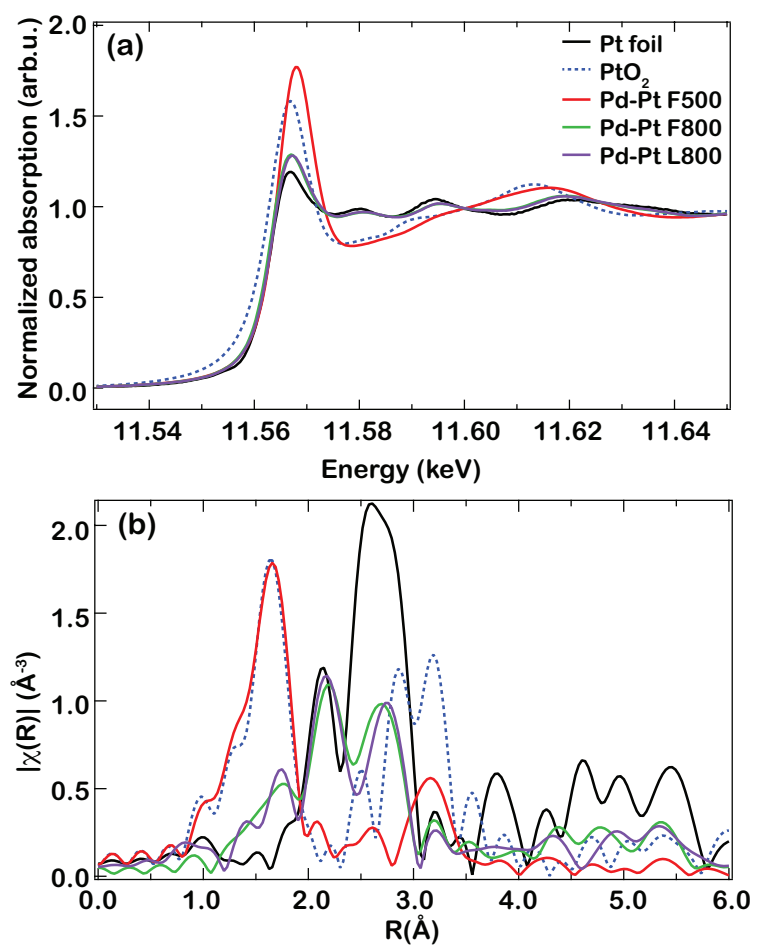

Figure 3: $\mathrm{Pt} \mathrm{L}_{I I I}$ edge ex situ XAS spectra from the as-prepared $\mathrm{Pd}-\mathrm{Pt} / \mathrm{Al}_{2} \mathrm{O}_{3}$ catalysts calcined at different temperatures. $\mathrm{Pt}$ foil and $\mathrm{PtO}_{2}$ are included as references. (a) XANES spectra and (b) Magnitude of Fourier Transformed EXAFS spectra (k-weight = 2). 

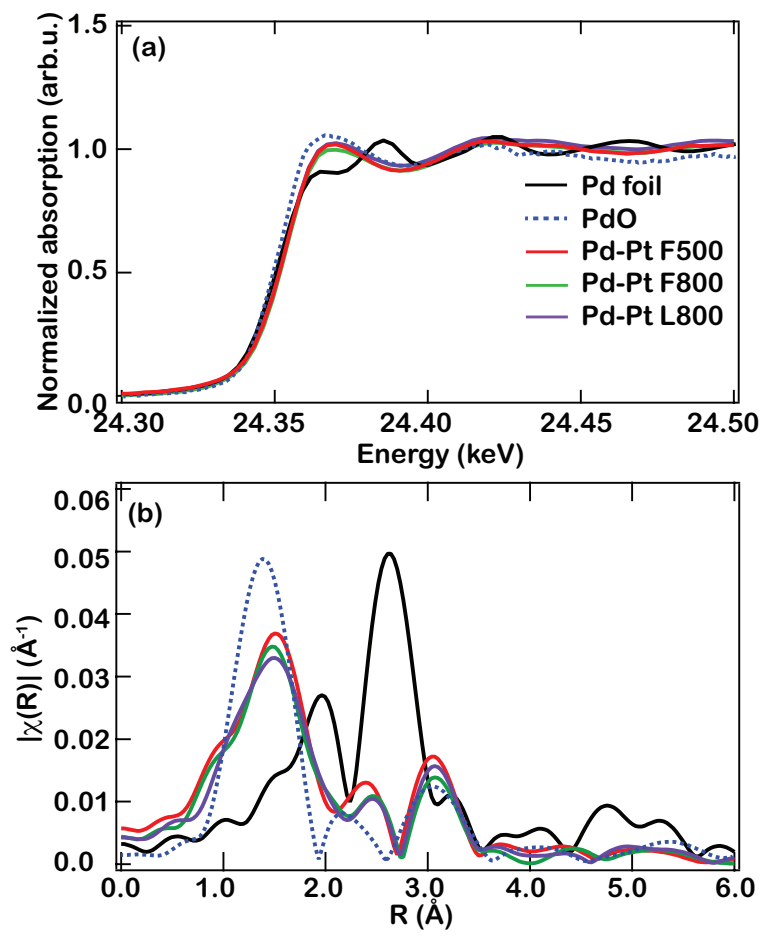

Figure 4: $\mathrm{Pd} \mathrm{K}$ edge ex situ XAS spectra from the as-prepared $\mathrm{Pd}-\mathrm{Pt} / \mathrm{Al}_{2} \mathrm{O}_{3}$ catalysts calcined at different temperatures. Pd foil and PdO are included as references. (a) XANES spectra and (b) Magnitude of Fourier Transformed EXAFS spectra (k-weight $=0$ ). 

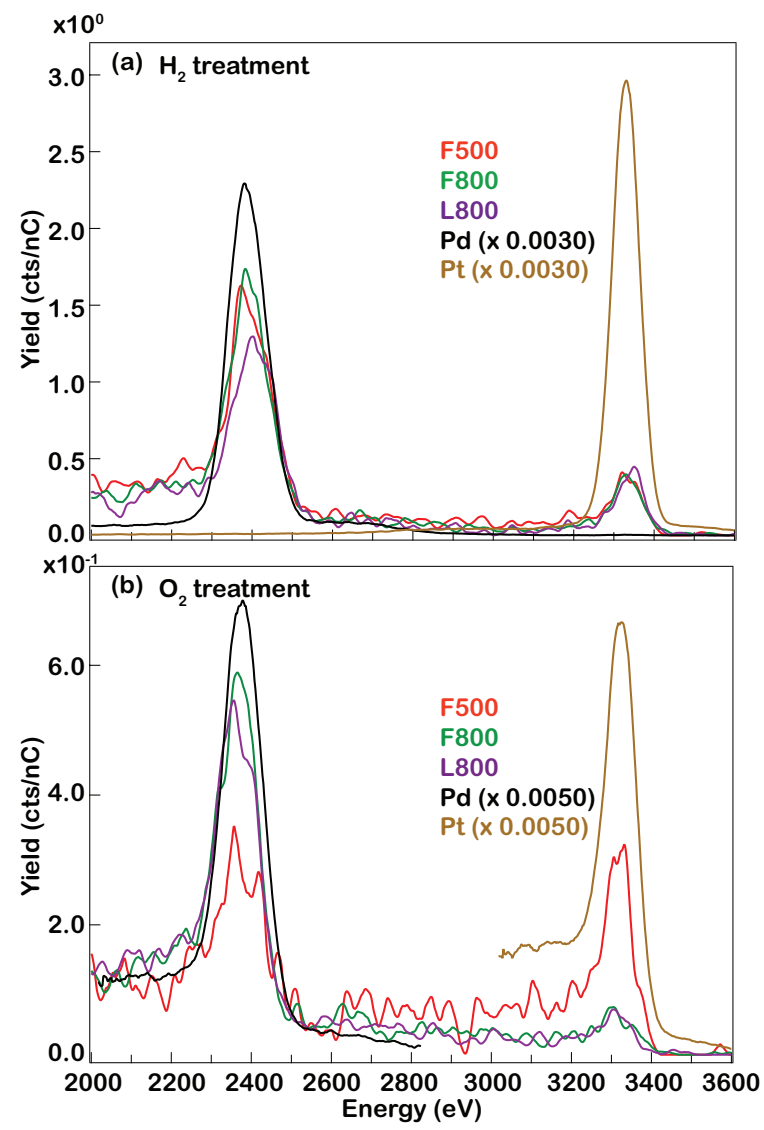

Figure 5: Ex situ LEIS results from the reduced (50 mbar $\mathrm{H}_{2}$ at $300{ }^{\circ} \mathrm{C}$ for $25 \mathrm{~min}$ ) (a) and oxidised (atomic oxygen at room temperature for $60 \mathrm{~min}$ ) (b) $\mathrm{Pd}-\mathrm{Pt} / \mathrm{Al}_{2} \mathrm{O}_{3}$ catalysts. $\mathrm{Pd}$ and $\mathrm{Pt}$ are included as references. 

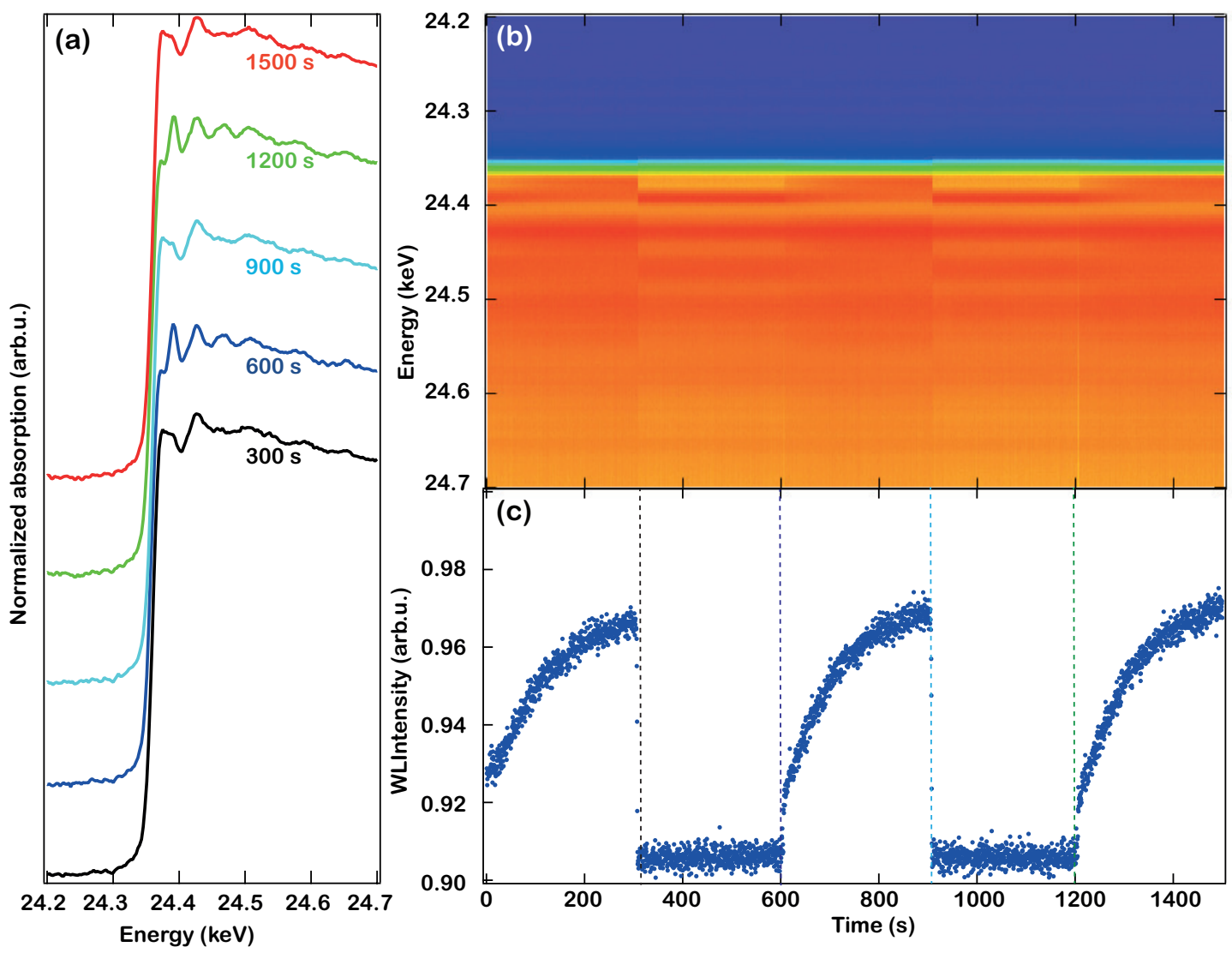

Figure 6: XAS spectra recorded during consecutive $300 \mathrm{~s}$ oxidising $\left(1.5 \% \mathrm{O}_{2}\right)$ and reducing $\left(2 \% \mathrm{H}_{2}\right)$ periods over $\mathrm{Pd}-\mathrm{Pt} / \mathrm{Al}_{2} \mathrm{O}_{3} \mathrm{~F} 500$ at $360{ }^{\circ} \mathrm{C}$.(a) XAS spectra recorded at the end of the oxidising and reducing periods. (b) Colour coded intensities of XAS spectra (blue:low intensity, red:high intensity) and (c) the XAS white line intensity at $24372 \mathrm{eV}$.

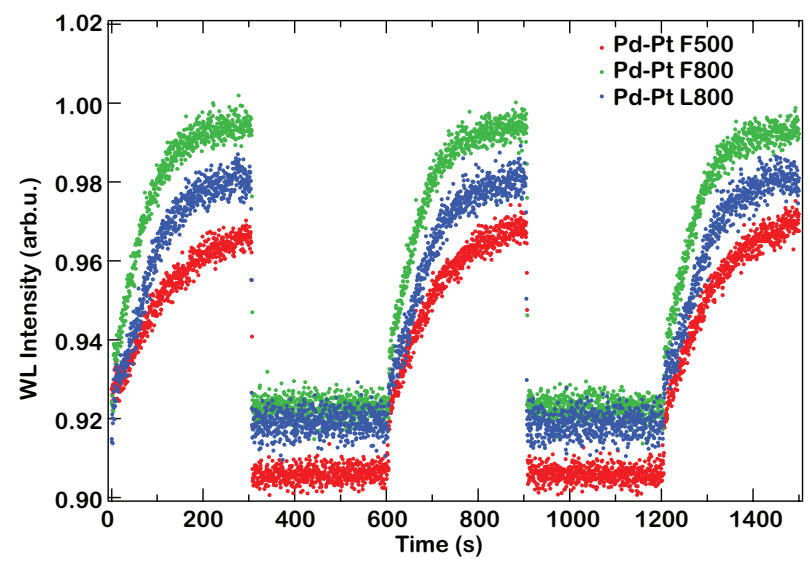

Figure 7: XAS white line intensity as a function of time during consecutive 300 sec. oxidising $\left(1.5 \% \mathrm{O}_{2}\right)$ and reducing $\left(2 \% \mathrm{H}_{2}\right)$ periods over the Pd-Pt/ $\mathrm{Al}_{2} \mathrm{O}_{3} \mathrm{~F} 500$ (red), F800 (green) and L800 (blue) samples at $360{ }^{\circ} \mathrm{C}$. 

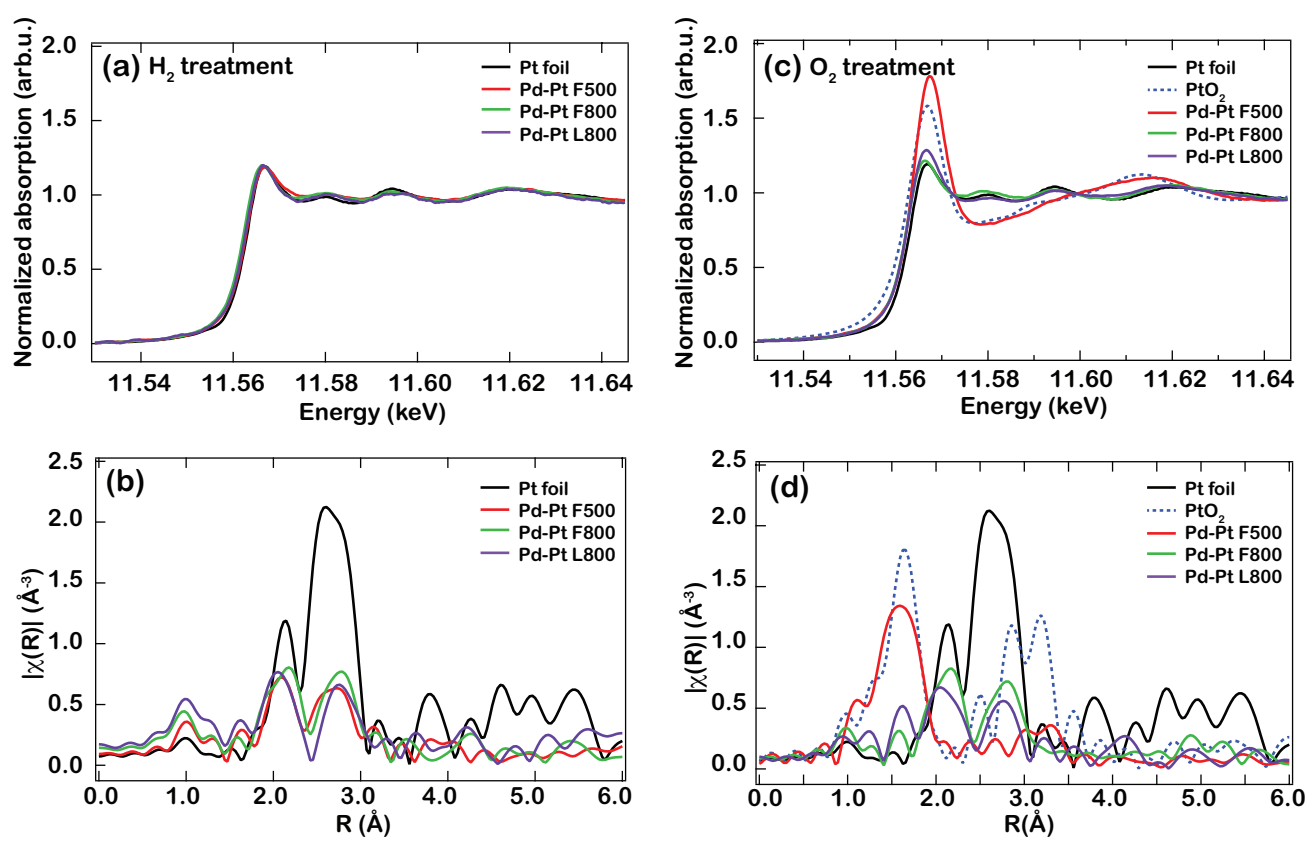

Figure 8: $\mathrm{Pt} \mathrm{L}_{I I I}$ edge in situ XAS spectra from the reduced (a-b) and oxidised (c-d) Pd$\mathrm{Pt} / \mathrm{Al}_{2} \mathrm{O}_{3}$ catalysts at $300{ }^{\circ} \mathrm{C}$. Pt foil and $\mathrm{PtO}_{2}$ are included as a reference. (a) and (c) XANES spectra and (b) and (d) Magnitude of Fourier Transformed EXAFS spectra (kweight $=2$ ). Note that the spectra from the bimetallic catalysts are taken in situ at $300{ }^{\circ} \mathrm{C}$, therefore the lower quality compared to Figure 3.

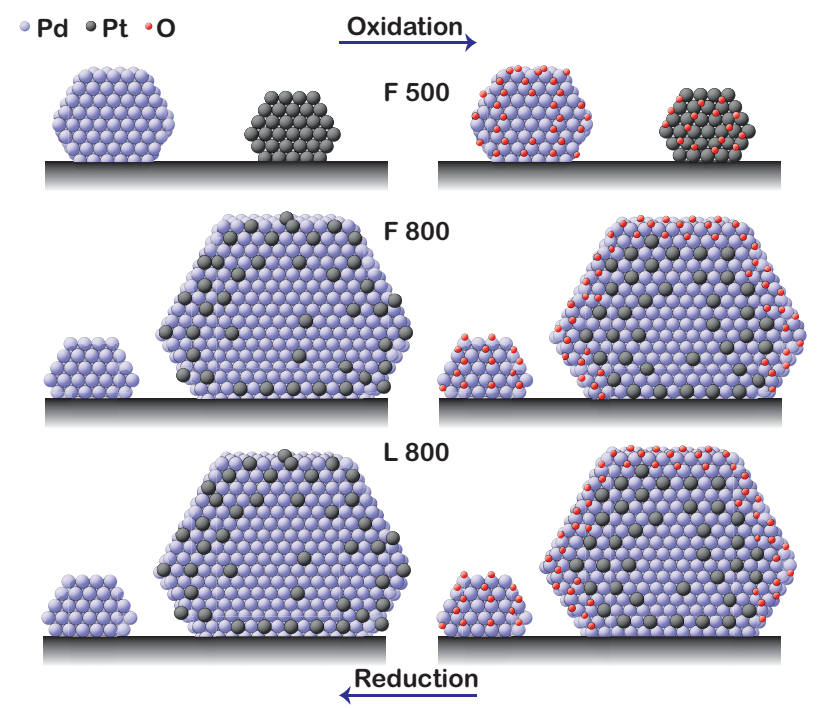

Figure 9: Proposed model for the Oxidation/Reduction behaviour of Pd-Pt catalysts based on the present observations. 


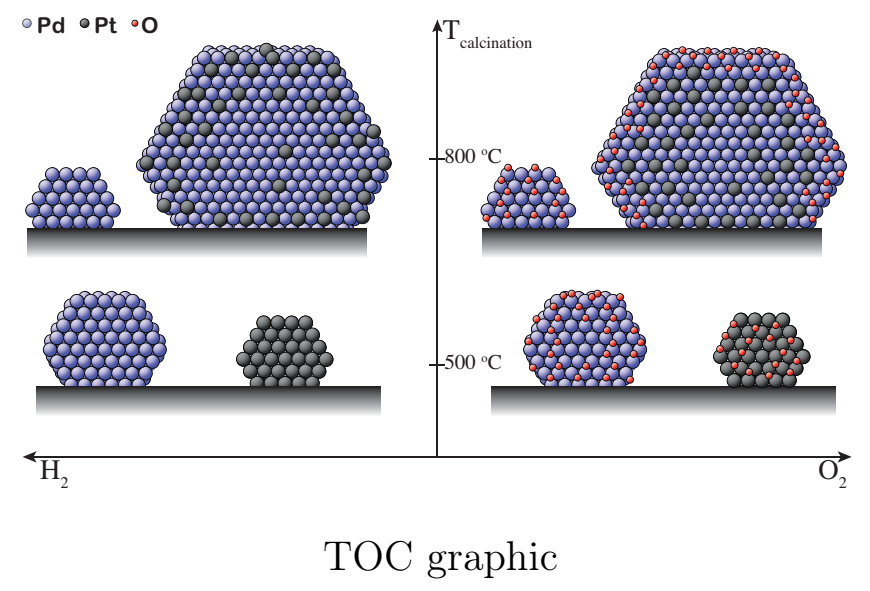

